\title{
Three distinctive new genera of Baetidae (Insecta, Ephemeroptera) from South America
}

\author{
C.R. Lugo-Ortiz ${ }^{1}$ \\ W.P. Mc Cafferty ${ }^{1}$
}

Keywords : Ephemeroptera, Baetidae, Adebrotus amazonicus, Tomedontus primus, Waltzoyphius fasciatus, new genera, new species, Brazil, Paraguay.

Three new genera of Baetidae (Ephemeroptera) are described from larvae from South America. Adebrotus Lugo-Ortiz \& McCafferty, n.gen., and its type species, A. amazonicus Lugo-Ortiz \& McCafferty, n.sp., were taken from Amazonas, Brazil. The genus possesses numerous unique mouthpart characteristics, including a labrum with distinct anteromarginal protrusions, a left mandible with the inner incisors rotated to a right angle with the flat plane of the mandible, a right mandible with a large denticle in the midregion of the mola, unusually shaped galealaciniae with distally pectinate setae, and an unusually shaped labium. Tomedontus Lugo-Ortiz \& McCafferty, n.gen., and its type species, T. primus Lugo-Ortiz \& McCafferty, n.sp., were taken from Amazonas and Pará, Brazil. The genus possesses a trapezoidal labrum lacking an anteromedial emargination, a distomedial process on the hypopharyngeal superlinguae, laterally denticulate mandibles, and unusually shaped maxillae and labium. Waltzoyphius McCafferty \& Lugo-Ortiz, n.gen., and its type species, W. fasciatus McCafferty \& Lugo-Ortiz, n.sp., were taken from Amazonas and Pará, Brazil, and Paraguarí, Paraguay. The genus is distinct in that the maxillae have only falcate denticles on the galealaciniae, the labium is unusually shaped, and the midsternum has an acute medial spur.

\section{Trois remarquables genres nouveaux de Baetidae (Insecta, Ephemeroptera) d'Amérique du Sud}

Mots clés : Ephéméroptères, Baetidae, Adebrotus amazonicus, Tomedontus primus, Waltzoyphius fasciatus, genres nouveaux, espèces nouvelles, B résil, Paraguay.

Trois genres nouveaux de Baetidae (Ephemeroptera) sont décrits à partir de larves récoltées en Amérique du Sud. Adebrotus Lugo-Ortiz \& McCafferty, n.gen., et son espèce type, A. amazonicus Lugo-Ortiz \& McCafferty, n.sp., proviennent de la province Amazonas, Brésil. Le genre possède de nombreux caractères unịques sur les pièces buccales, incluant un labre avec des protubérances marginales antérieures, une mandibule gauche dont les incisives internes sont orientées perpendiculairement au plan de la mandibule, une mandibule dröite avec un grand denticule dans la région molaire moyenne, des galealaciniae de formé originale avec des soies pectinées distalement, et un labium de morphologie inusitée. Tomedontus Lugo-Ortiz \& McCafferty, $\mathrm{n}_{\text {:gen. }}$. et son espèce type, T. primus Lugo-Ortiz \& McCafferty, n.sp., proviennent des provinces Amazonas et Pará, Brésil. Le genre possède un labre trapézoïdal dépourvu d'indentation médíane antérieure, un hypopharynx portant un processus médiodistạl sụr les superlinguae, des mandibules dentelées latéralement ainsi que des maxilles et un labium de formes inusitées. Waltzoyphius McCafferty \& Lugo-Ortiz, n.gen., et son espèce type, W. fasciatus McCafferty \& Lugo-Ortiz, n.sp., proviennent d'Amazonas ét Pảrá, Brésil, ainsi que du département de Paraguarí, Paraguay. Le genre se caractérise par ses maxilles ne possédant que des denticules falciformes sur les galealaciniae, son labium de morphologie inusitée et son mesosternum porteur d'un éperon médian.

\section{Introduction}

The faunistics of the mayfly family Baetidae in South America is typical of most other mayfly families in the Southern Hemisphere in that it is poorly known.

1. Department of Entomology, Purdue University, West Lafayette, IN 47907, U.S.A.
Treatmentis of baetids are mostly based on outdated generic concepts, as demonstrated, for example, by the recent revisionary works of Waltz \& McCafferty (1985, 1987a, b). Currently, we can account for only nine genera in South America : Acerpenna Waltz \& McCafferty, Baetodes Needham \& Murphy, Bernerius Waltz \& McCafferty, Callibaetis Eaton, Camelobaetidius Demoulin, Cloeodes Traver, Guajirolus Flowers, Harpagobaetis Mol, and Moribaetis Waltz \& McCaf- 
ferty. We have not been able to confirm reports of Baetis Leach, Cloeon Leach, or Pseudocloeon Klapálek (see McCafferty et al. 1992). The number of confirmed genera in South America stands in marked contrast with that of North America north of Mexico, where 20 have been confirmed (McCafferty \& Waltz 1990, 1995). The relative dearth of information on the biodiversity of South American Baetidae is explicable strictly from a lack of collected field data. The abundance and heterogeneity of freshwater habitats in South America (Lewis et al. 1995) predicts a diverse fauna, and Edmunds (1972) asserted that the family probably originated in South America and is most diverse on that continent.

Our present interest to assess the faunistics and biogeographic affinities of baetids in South America has led us to the discovery of several new taxa. Recently, for example, we discovered a highly atypical genus whose male adults lack the turbinate portion of the compound eyes (Lugo-Ortiz \& McCafferty, in press). Herein, we describe three unusual new genera from Brazil and Paraguay. Although the new taxa are based on larvae only, the descriptions of these unusual genera is in keeping with our philosophy of expediting the description of Neotropical diversity in areas of present and impending habitat degradation and destruction. The material studied is housed in the following institutions : Purdue Entomological Research Collection (PERC), West Lafayette, Indiana ; United States National Museum (USNM), Washington, D.C. ; and Zoologische Staatssammlung (ZS), Munich, Germany.

\section{Adebrotus Lugo-Ortiz \& McCafferty, n.gen.}

\subsection{Description}

Mature larva

- Head

Antenna with bare scapes and pedicels. Frontal keel absent.

Labrum (Fig. 1) basally broad, with one small medial anteromarginal protrusion and one large and one small submedial anteromarginal protrusions on both sides.

Hypopharynx (Fig. 2)with relatively broad lingua and moderately distolaterally expanded superlinguae.

Left mandible (Fig. 3) with incisors basally separated ; inner set of incisors at right angles with outer set ; prostheca parallel to inner set of incisors, slender, with row of simple setae, and denticulate ; long, robust, simple setae present between prostheca and mola ; triangular process at base of mola with two small, sharp denticles basally on outer margin and simple setae basally on medial margin ; mola reduced ; distally pectinate setae present distomedially at base of mola. Right mandible (Fig. 4) with incisors basally separated ; inner set of incisors at oblique angle with outer set ; prostheca robust, with long, slender, branched seta in midregion ; tuft of long, slender setae at base of mola ; mola with large, blunt denticle in midregion ; distally pectinate setae present distomedially at base of mola.

Maxillae (Fig. 5) elongate, basally broad, tapering distally ; palps two-segmented ; galealaciniae with sharp denticles and long, robust, distally pectinate setae.

Labium (Fig. 6) with palps three-segmented ; palp segment 1 broad and short; segment 2 long and slender, nearly $1.5 x$ length of segment 1 ; segment 3 short and conical, nearly $0.20 x$ length of segment 2 ; glossae broad, somewhat longer than paraglossae ; paraglossae narrow and elongate, subequal to glossae.

- Thorax

Hindwingpads absent

Legs (Fig. 7) without villopore ; femora elongate, distally round, anterior and posterior margins subparallel ; tibiae elongate, nearly $0.75 \mathrm{x}$ length of femora ; tarsi elongate, subequal to tibiae ; tarsal claws (Fig. 8) elongate, with single row of very small denticles.

- Abdomen

Tergal surfaces without scales or scale bases (Fig. 9).

Gills on abdominal segments 1-7, plate-like, elongate (as in Fig. 18).

Paraprocts without prolongation.

Three caudal filaments present.

Alate stages

Unknown.

\subsection{Etymology}

Masculine, an arbitrary combination of the Greek words adelos (unknown) and brotus (edible). It is an allusion to the unknown feeding habits probably related to the highly specialized mouthparts of the larvae.

\subsection{Types species}

$$
\begin{aligned}
& \text { Adebrotus amazonicus Lugo-Ortiz \& McCafferty } \\
& \text { n.sp. }
\end{aligned}
$$

\subsection{Distribution}

Brazil : Amazonas.

\subsection{Discussion}

Adebrotus is unique in Baetidae, showing several characters not known in other members of the family. The labrum (Fig.1) has distinct anteromedial humps, 
and the anterior margin does not possess abundant fine, simple setae as in most other baetids. The left mandible (Fig. 3) is unique in that the inner set of incisors is rotated to a right angle with the outer set. Also, the margin between the prostheca and mola has elongate, robust setae, and the mola is relatively reduced.The right mandible (Fig. 4) has a reduced inner set of incisors, and the mola has a distinct, large, blunt denticle in the midregion. The maxillae (Fig. 5) are distinctly acute distally, and the galealaciniae possess only a set of robust, distally pectinate setae. The labium (Fig. 6) shows a unique combination of elongate, broad glossae ; elongate, slender paraglossae ; and elongate, slender palp segments 2 .

The peculiar morphology of the mouthparts of Adebrotus suggests that it has highly specialized feedings habits, possibly correlated to the waterfall habitat from where it was collected. It is possible the mouthparts are adapted for grazing on large periphyton, but we do not rule out the possibility that they may manipulate small prey also.

Adebrotus provisionally appears to belong to Cloeoninae on the basis of the basally-separated incisors. However, we have not seen any Cloeoninae with the inner set of incisors of the left mandible at right angles with the outer set, nor with distally acute maxillae. Until the adults are known, the precise placement of Adebrotus within Baetidae will remain tentative.

\subsection{Adebrotus amazonicus Lugo-Ortiż \& McCaf- ferty, n.sp.}

\subsubsection{Description}

\section{Mature larva}

Body length : $4.0 \mathrm{~mm}$; caudal filaments : unknown. General color light brown.

- Head

Coloration light brown, with no distinct pattern.

Labrum (Fig. 1) anteriorly with 9-10 elongate, robust, simple setae marginally on each side of midline.

Hypopharynx (Fig. 2) with short, fine, simple setae distally on lingua and elongate, fine, simple setae distally on superlinguae.

Left mandible (Fig. 3) with outer set of incisors with three large and three small denticles ; inner set of incisors with four denticles; prostheca with seven to eight denticles ; eight long, robust, simple setae between prostheca and mola ; four to five distally pectinate setae present distomedially. Right mandible (Fig. 4) with outer set of incisors with three denticles ; inner set of incisors with two denticles ; four to five distally pectinate setae present distomedially.
Maxillae (Fig. 5) with palps extending beyond galealaciniae ; galea-laciniae with two sharp denticles and four to five long, robust, distally pectinate setae ; three to four long, simple setae medially in midregion.

Labium (Fig. 6) with palp segments 2 and 3 with scattered fine, simple setae laterally and medially ; glossae with scattered short, simple setae marginally and basally on ventral surface ; paraglossae with one row of 14-16 elongate simple setae marginally and 810 elongate, simple setae ventrally.

\section{- Thorax}

Coloration light brown, with no distinct pattern.

Legs (Fig. 7) light brown ; femora dorsally with 9-10 long, simple setae dorsally and ventrally bare ; tibia ventrally with numerous small, simple setae ; tarsi dorsally bare, ventrally with two rows of small, simple setae ; tarsal claws (Fig. 8) with 8-10 denticles.

- Abdomen

Coloration light brown, with no distinct pattern.

Tergal posterior spination (Fig. 9) irregular.

Gills $1-7$ elongate, nearly $1.25 \mathrm{x}$ length of corresponding segment, poorly tracheated, marginally serrate (as in Fig. 18).

Paraprocts with sharp spines, gradually increasing in length towards posterior margin.

Alate stages

Unknown:

\subsubsection{Material examined}

Holotype : Mature female larva, Brazil, Amazonas State, Cachoeira do Traira Cr, waterfall, nr Rio Cuieiras, N of Manaus, 16-XII-1960, E.J. Fittkau (PERC). Mouthparts, right foreleg, and tergum 5 mounted on slide (Euparal medium).

\subsubsection{Etymology}

The specific epithet is a geographic reference to the state of Amazonas in Brazil, from where the type specimen was collected.

\subsubsection{Discussion}

Although the material examined consists of one larva only, we describe it herein because of its numerous unique characteristics and because the species appears to be rare, and possibly threatened, in South America. The degree of variability within $A$. amazonicus cannot be ascertained at this moment, but we do not expect much variability if it is highly specialized, as it is suggested by the morphology of the mouthparts (see above). Nor can we presently determine diagnostic species characters because the morphological peculiarities of A. amazonicus do not allow a precise assessment as 


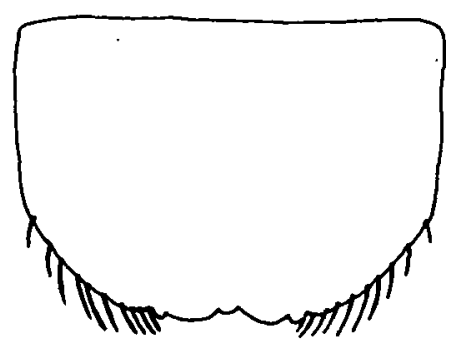

1

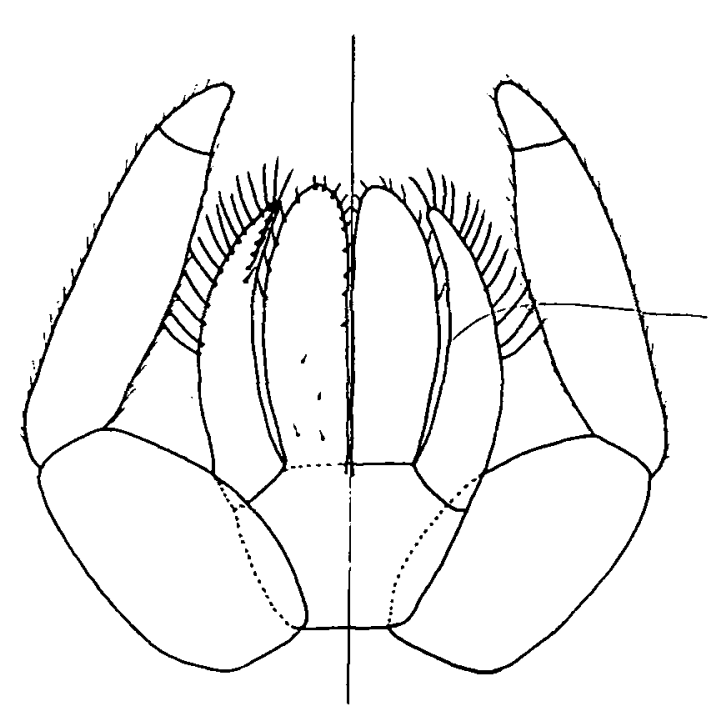

6

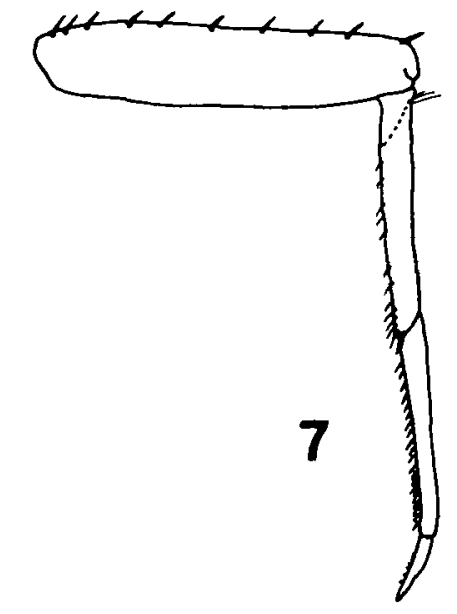

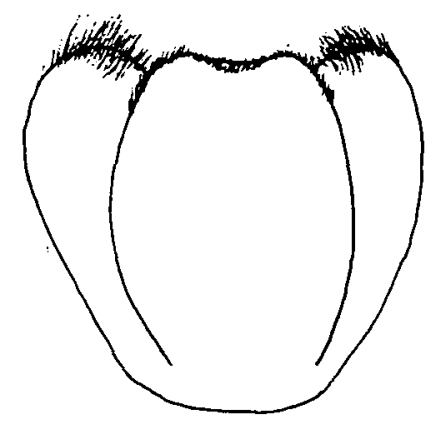

2

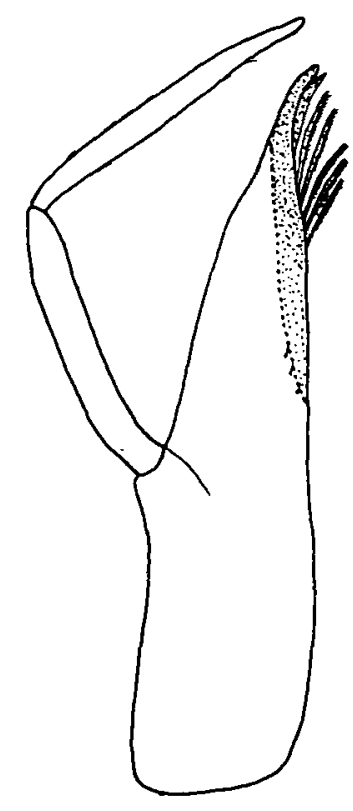

5
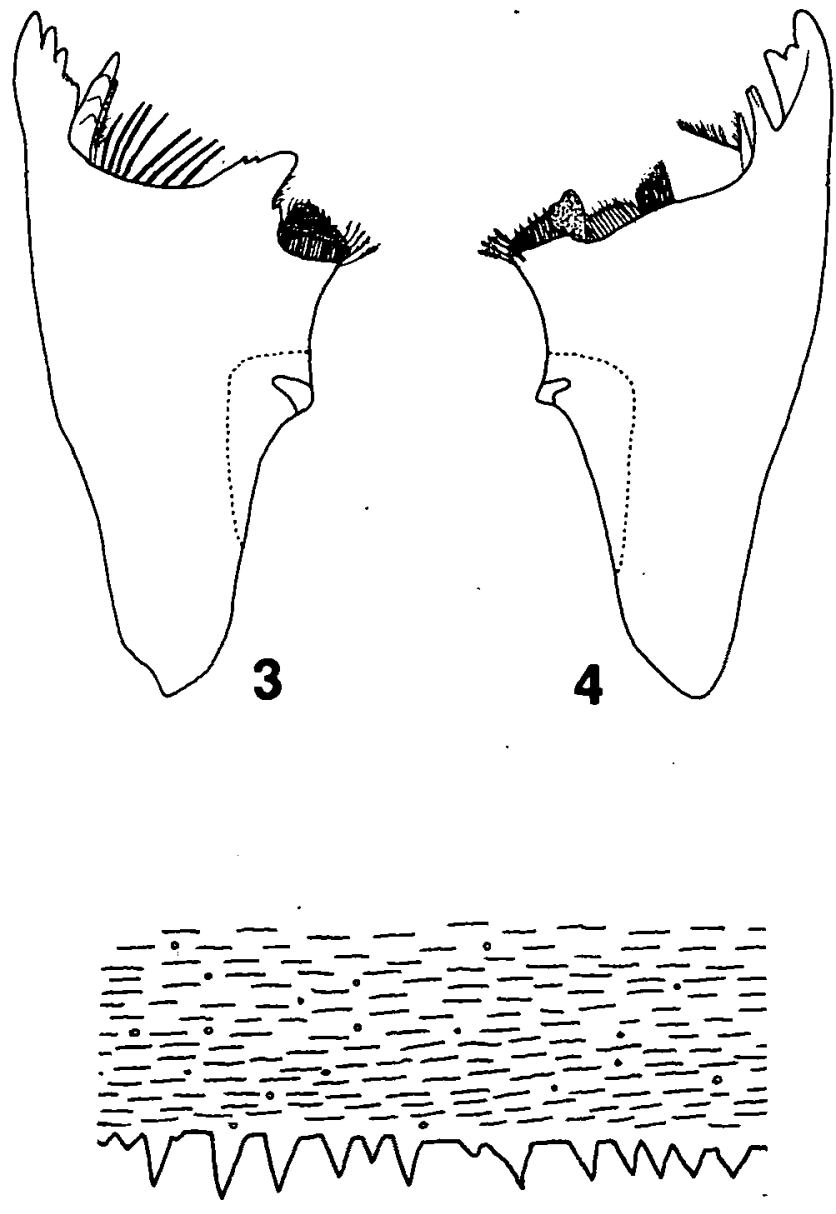

9

Fig. 1 to 9 . Structures of Adebrotus amazonicus, larvae. $1:$ labrum. $2:$ hypopharynx. $3:$ left mandible. $4:$ right mandible. $5:$ right maxilla. 6 : labium (left-ventral ; right-dorsal). 7 : right foreleg. $8:$ tarsal claw. $9:$ tergal surface.

Fig. 1 à 9 . Structures larvaires d'Adebrotus amazonicus. $1:$ labre. $2:$ hypopharynx. $3:$ mandibule gauche. $4:$ mandibule droite. $5:$ maxille droite. $6:$ labium (à gauche : vue ventrale; à droite : vue dorsale). $7:$ patte antérieure droite. $8:$ griffe tarsale. $9:$ surface tergale. 
to which characters might vary, and how. However, it is possible that, as in other baetid genera, color differences, leg setation, and tergal and paraproctal spination may eventually serve to diagnose species in case that new species within Adebrotus are discovered.

\section{Tomedontus Lugo-Ortiz \& McCafferty, n.gen.}

\subsection{Description}

Mature larva

- Head

Antennae with bare scapes and pedicels. Frontal keel present.

Labrum (Fig. 10), narrow basally, trapezoidal, without anteromedial emargination.

Hypopharynx (Fig. 11) broad ; linguae distolaterally expanded and acute ; superlinguae distolaterally expanded, with distal medial process.

Left mandible (Fig. 12) with incisors fused and numerous minute denticles laterally, increasing in size distally ; small tuft of short, fine, simple setae at base of incisors ; prostheca denticulate distally ; margin between prostheca and mola with numerous minute denticles and short, simple setae; sharp triangular process at base of mola. Right mandible (Fig. 13) with incisors fused and numerous minute denticles laterally, increasing in size distally; row of short, fine, simple setae on medial margin of incisors ; small tuft of short, fine, simple setae at base of incisors ; prostheca setose distally ; margin between prostheca and mola with numerous minute denticles and short, simple setae ; tuft of short, fine simple setae at base of mola.

Maxillae (Fig. 14) short and robust; palps two-segmented ; galealaciniae with long, robust and long, slender denticles.

Labium (Fig. 15) with palps three-segmented; segment 1 elongate and slender ; segment 2 elongate and slender, nearly $1.25 x$ length of segment 1 , with moderate, distomedially acute process ; segment 3 short and round ; glossae basally broad, distally round, shorter than paraglossae ; paraglossae basally narrow, distally round.

\section{- Thorax}

Hindwingpads absent.

Legs (Fig. 16) without villopore ; femora elongate, distally round, anterior and posterior margins subparallel ; tibiae elongate, subequal to femora ; tarsi nearly $0.75 x$ length of tibiae ; tarsal claws single row of denticles.

\section{- Abdomen}

Tergal surfaces with scales and scale bases (Fig. 17).

Gills (Figs. 18-19) on abdominal segments 1-6, plate-like, broad.

Paraprocts (Fig. 20) without prolongation.

Three caudal filaments present ; terminal filament subequal to cerci.

\section{Alate stages}

Unknown.

\subsection{Etymology}

Masculine, an arbitrary combination of the Greek words tomeus (incisor) and odontos (tooth). It is an allusion to the laterally toothed incisors of the mandibles.

\subsection{Type species}

Tomedontus primus Lugo-Ortiz \& McCafferty n.sp.

\subsection{Distribution}

Brazil : Amazonas, Pará.

\subsection{Discussion}

Tomedontus shows several distinctive features that will readily distinguish it from other baetid larvae. The trapezoidal shape of the labrum (Fig. 10) is unique among baetids. The hypopharynx (Fig. 11) is unusually distolaterally expanded for a baetid, and the distal processes of the superlinguae are not found in other members of the family. The fused mandibular incisors (Figs. 12-13) uniquely possess numerous minute lateral denticles. The maxillae (Fig. 14) have distinct slender, falcate denticles on the galealaciniae. The labium (Fig. 15) shows an unusual combination of short, distally round glossae with elongate, simple setae, distally expanded paraglossae and palp segments 2 with a moderate, distomedially acute process.

The phylogenetic relationships of Tomedontus cannot be determined at this moment because all of the above characters are autapomorphies, and we cannot presently identify characters that would tie it to other baetid genera. It appears, however, that Tomedontus belongs to Baetinae because it possesses fused mandibular incisors. The lack of punctures on the cuticle and round apices of the femora exclude Tomedontus from Callibaetinae. Within Baetinae, the absence of the villopore excludes Tomedontus from the Baetis complex, and the lacck of setae on the dorsal surface' of the glossae excludes it from the Indobaetis complex (see Waltz et al. 1994). 


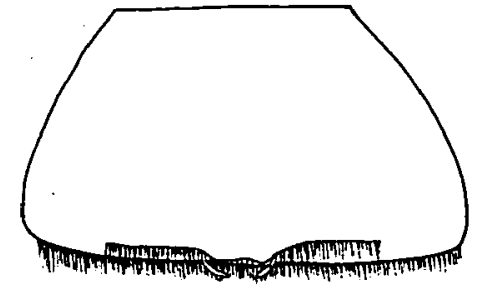

10

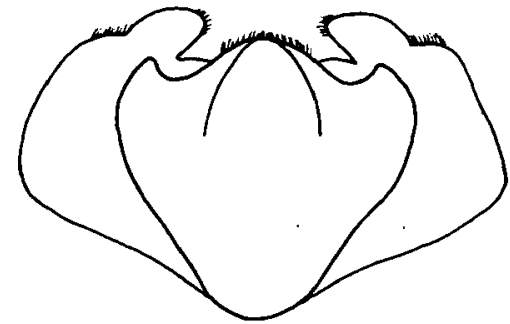

11

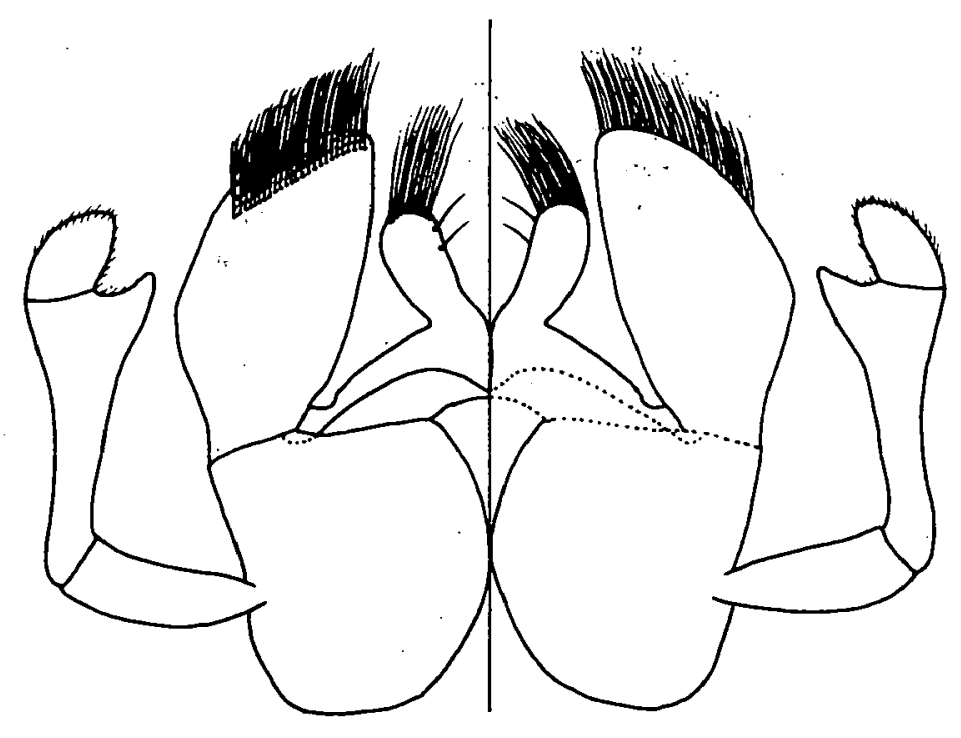

15

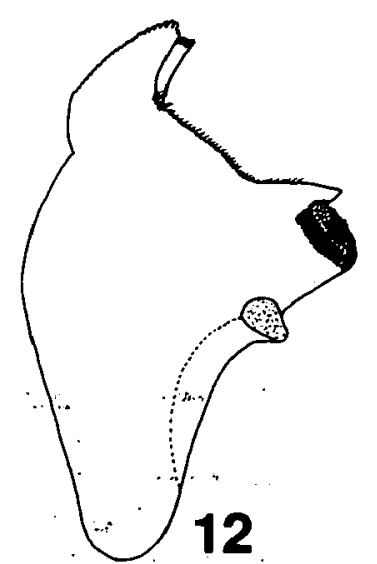

13
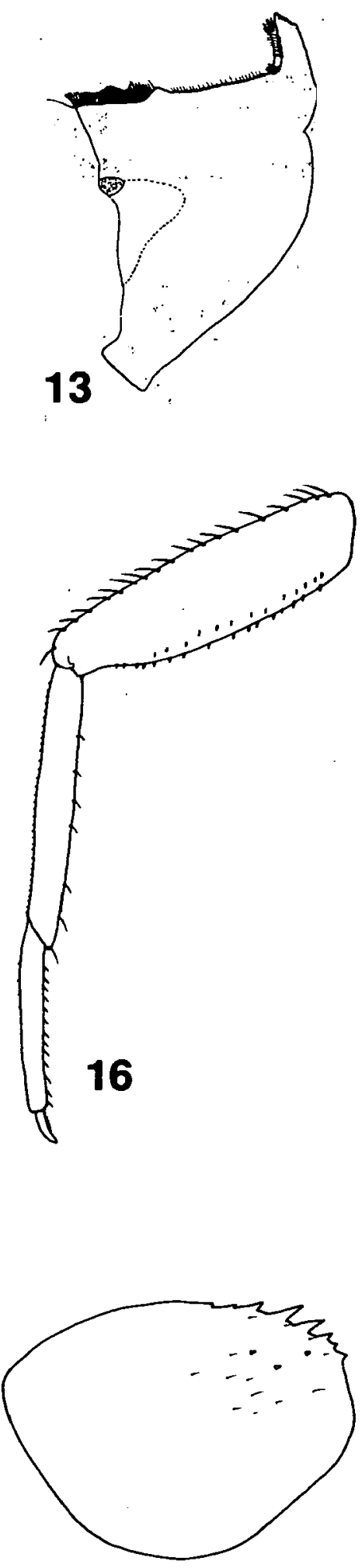

20

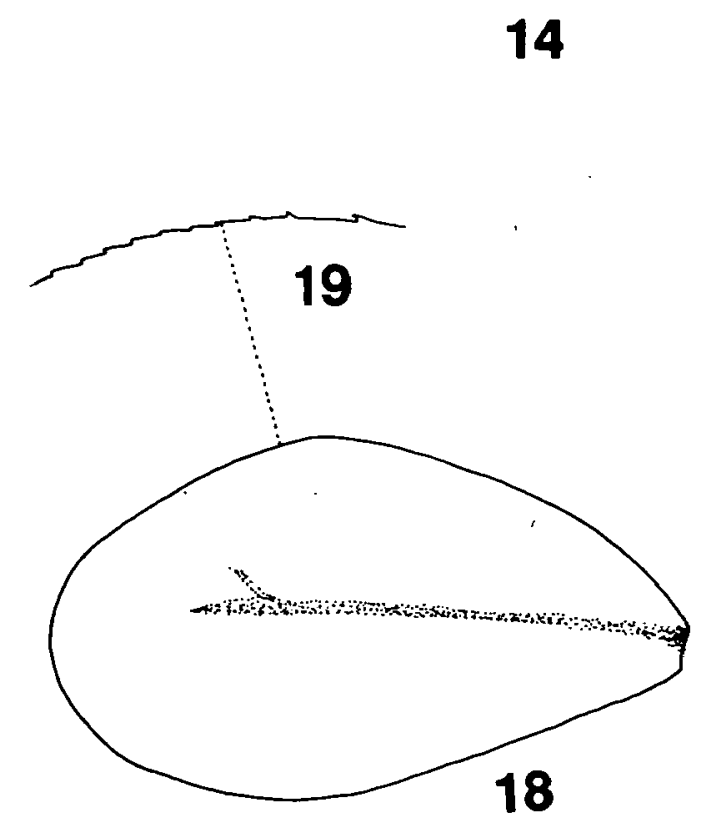

18

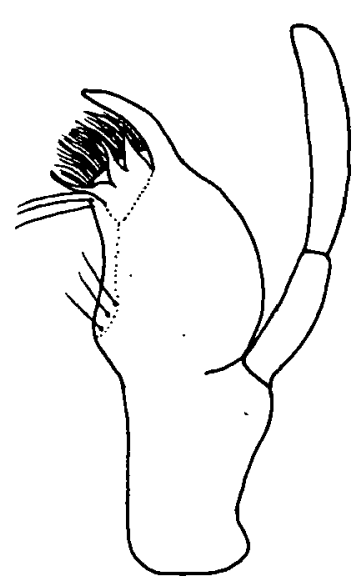

14

\section{7}

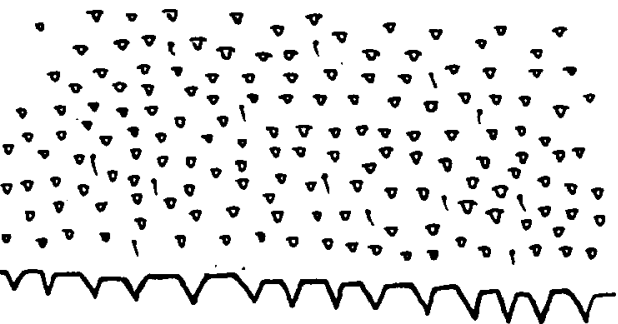




\subsection{Tomedontus primus Lugo-Ortiz \& McCafferty, n.sp.}

\subsubsection{Description}

\section{Mature larva}

Body length : 4.8-5.1 mm ; caudal filaments : 5.8-6.0 $\mathrm{mm}$. General color yellow-brown.

- Head

Coloration yellow-brown, with no distinct pattern.

Labrum (Fig. 10) anteriorly with fine, simple setae marginally and submarginally and one submarginal, small, spatulate seta submedially on each side of midline.

Hypopharynx as in Figure 11 with fine, simple setae distally on linguae and superlinguae.

Left mandible (Fig. 12) with 15-20 denticles laterally, becoming larger distally. Right mandible (Fig. 13) with 15-20 denticles, becoming larger distally.

Maxillae (Fig. 14) with palps subequal to galealaciniae ; galealaciniae with one large, sharp denticle and three slender, falcate denticles ; three long, simple setae medially in midregion.

Labium (Fig. 15) with palp segments 2 and 3 with scattered short, fine, simple setae on outer and medial margins ; glossae with two rows of long, simple setae distally ; paraglossae with three rows of long, simple setae distally.

\section{- Thorax}

Coloration yellow-brown, with no distinct pattern.

Legs (Fig. 16) yellow-brown ; femora dorsally with 18-20 long, simple setae and ventrally with numerous short, simple setae ; tibiae dorsally with numerous short, simple setae dorsally and ventrally with seven to eight setae of medium length ; tarsi dorsally with three to four short, simple setae and ventrally with $10-12$ setae of medium length ; tarsal claws with six to seven small denticles.

\section{- Abdomen}

Coloration yellow-brown, with no distinct pattern.

Tergal surfaces (Fig. 17) with abundant scales and scale bases ; posterior margins with short, sharp spines.

Gills (Fig. 18) nearly $1.25 x$ length of corresponding segment, poorly tracheated, marginally serrate (Fig. 19).

Paraprocts (Fig. 20) with irregular marginal spination and sparse fine, simple setae and scales on surface.

Caudal filaments yellow-brown to pale yellow. Cerci with six to eight long, simple setae medially on each segment ; terminal filament with six to eight long, simple setae laterally on each segment.

\section{Alate stages}

Unknown.

\subsubsection{Material examined}

Holotype : Mature female larva, Brazil, Amazonas State, Gigante $\mathrm{Cr}$, rapids, Reserva Duke, $\mathrm{N}$ of Manaus, 4-VII-1961, E.J. Fittkau (PERC). Paratypes : One larva, Brazil, Amazonas State, Gigante $\mathrm{Cr}$, nr Ponta Negra, Rio Negro, N of Manaus, 23-VI-1961, E.J. Fittkau (PERC) ; one larva Brazil, Amazonas State, Passarinho Cr, Reserva Duke, N of Manaus, 27-VI-1961, E.J. Fittkau (ZS) ; one larva, Brazil, Amazonas State, Passarinho Cr, Roca Antônio, Santo Antônio, 15 km N of Manaus, 13-XII-1961, E.J. Fittkau (PERC). Additional material : Fifteen larvae, Brazil, Amazonas State, Araeu Cr, $15 \mathrm{~km}$ from Manaus, rd nr Rio Branco, 8-VI1962, E.J. Fittkau (PERC) ; one larva, Brazil, Amazonas State, Passarinho Cr, Reserva Duke, $\mathrm{N}$ of Manaus, 27-VI-1961, E.J. Fittkau (ZS) ; one larva, Brazil, Pará State, Rio Axindéua, 10-XI-1953, H. Sioli (PERC).

\subsubsection{Etymology}

The specific epithet is a Latin word for first. It is reference to the species being the first described in the genus.

\subsubsection{Discussion}

Because only $T$. primus is known, we cannot determine which constitute reliable characters for species discrimination. However, we are confident that the larvae examined belong to only one species because they were consistent in general body coloration, labial morphology, labral and leg setation, mandibular denticulation, and tergal and paraproctal spination. These characters have been shown to vary among species in other baetid genera, and it is possible that other new species in Tomedontus may show some variation with respect to any of them.

\section{Waltzoyphius McCafferty \& Lugo-Ortiz, n.gen.}

\subsection{Description}

Mature larva

- Head

Antennae with bare scapes and pedicels. Frontal keel absent.

Labrum (Fig. 31) basally broad, with shallow anteromedial emargination.

Hypopharynx (Fig. 21) with broad lingua and moderately distolaterally expanded superlinguae. 


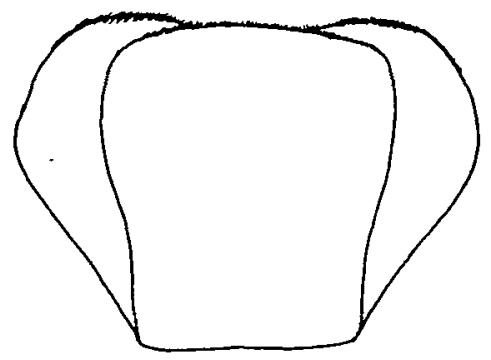

21

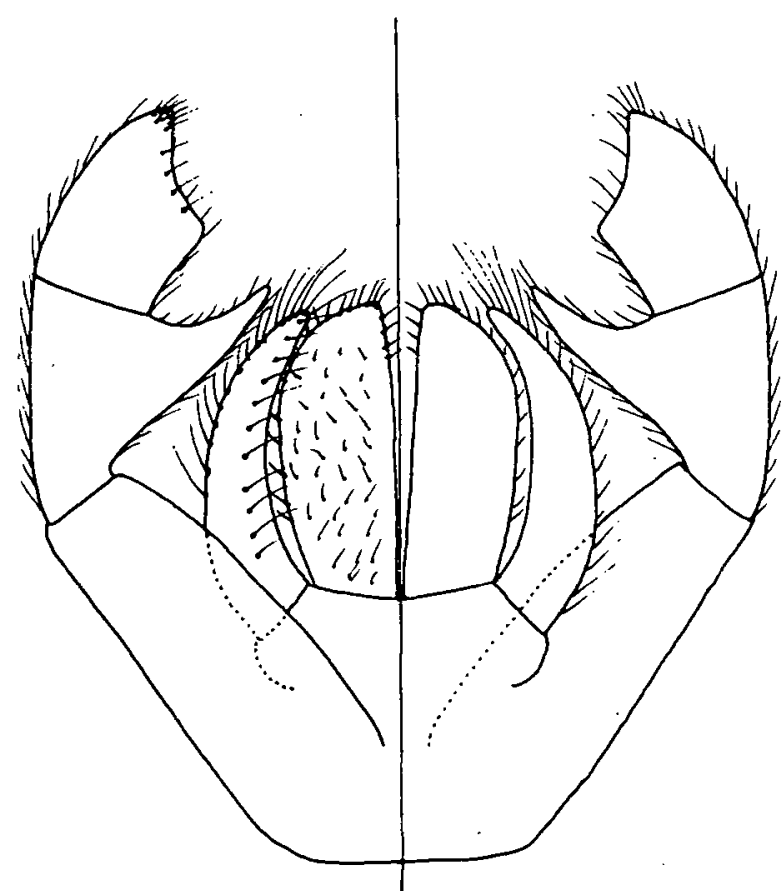

25
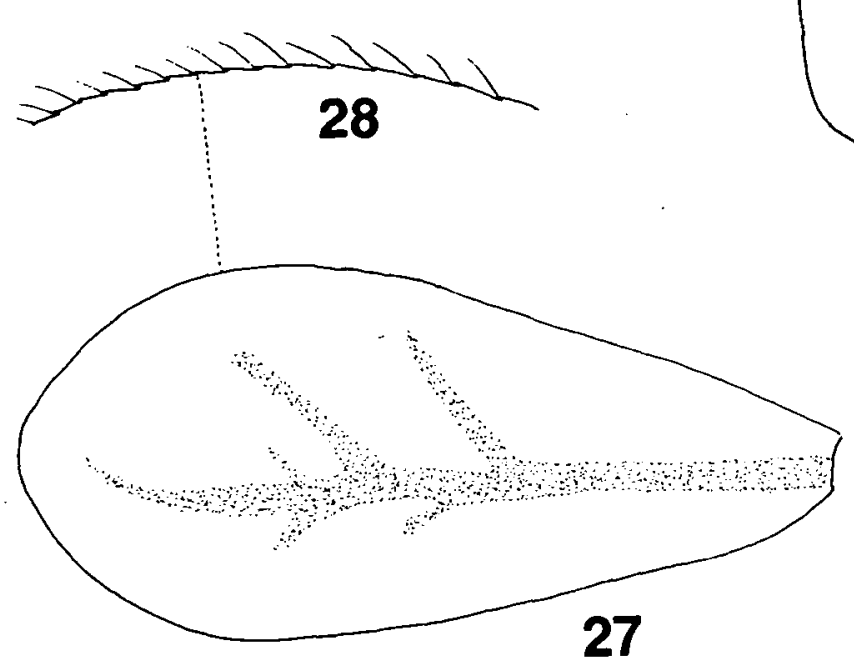
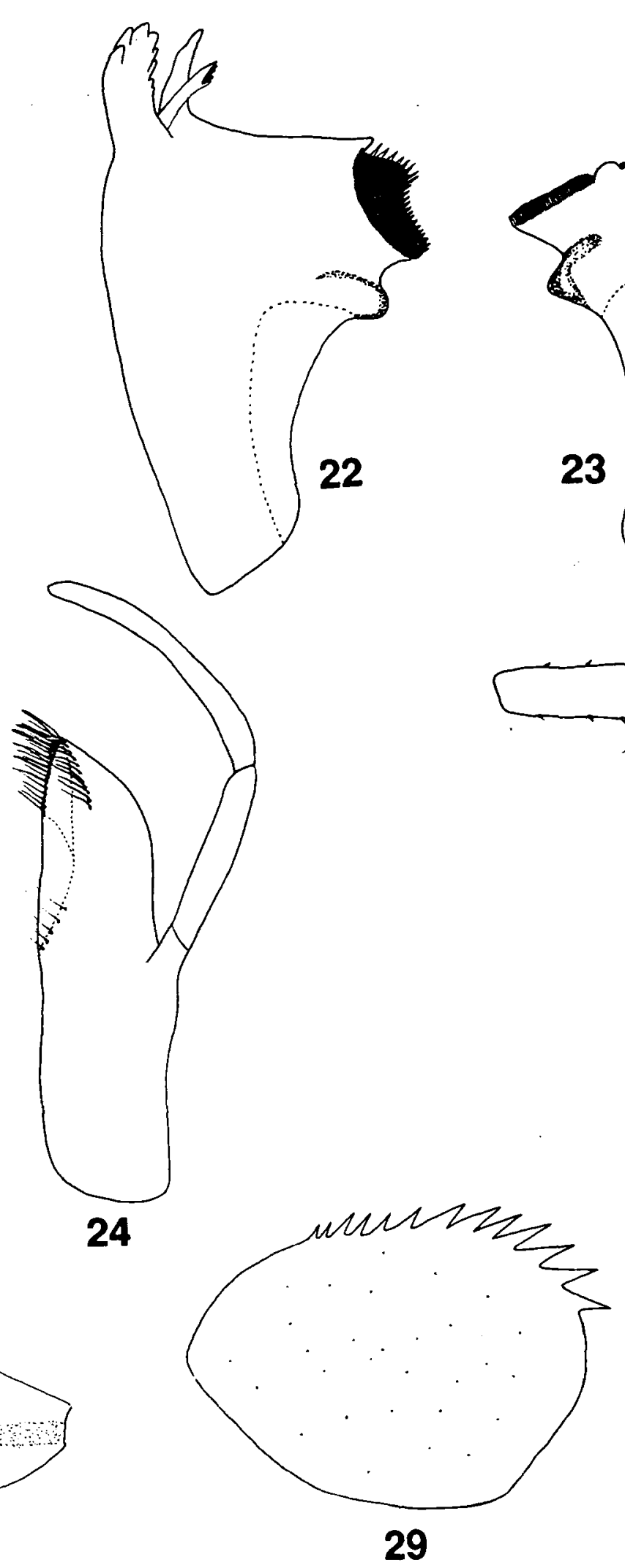
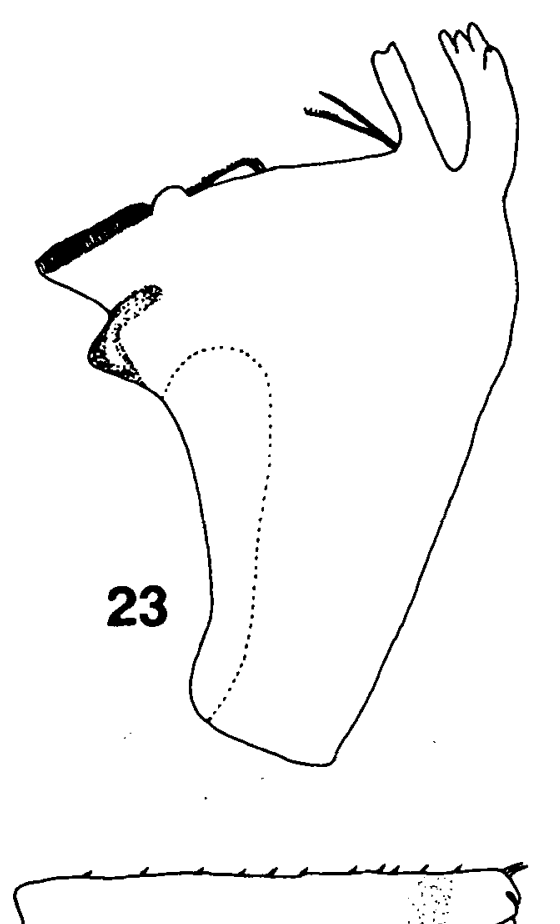
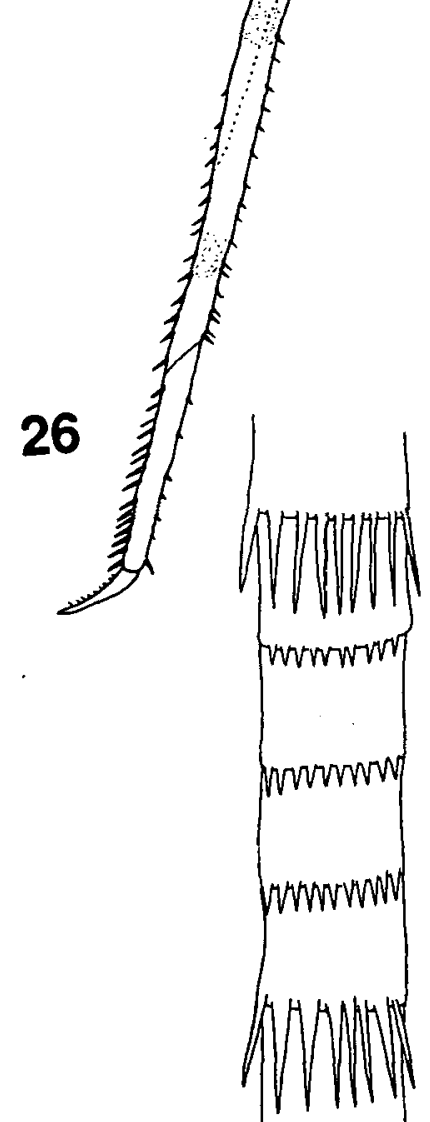

30.

Fig. 21 to 30 . Structures of Waltzoyphius fasciatus, larvae. 21 : hypopharynx. $22:$ left mandible. $23:$ right mandible. $24:$ right maxilla. 25 : labium (left-ventral ; right-dorsal). $26:$ left foreleg. $27:$ gill $6.28:$ detail of gill $6.29:$ paraproct. $30:$ detail of cerci (lateral)

Fig. 21 à 30. Structures larvaires de Waltzoyphius fasciatus. $21:$ hypopharynx. $22:$ mandibule gauche. $23:$ mandibule droite. $24:$ maxille droi-

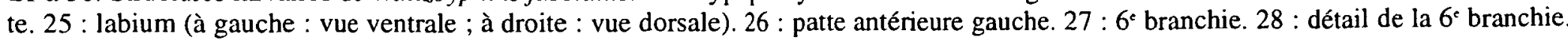
29 : paraprocte. 30 : détail des cerques (vue latérale). 
Mandibles (Figs 22-23) with two basally-separated sets of incisors. Prostheca of left mandible (Fig. 22) distally denticulate and with fine setae. Prostheca of right mandible (Fig. 23) consisting of one elongate, simple seta and one elongate, distally branched seta.

Maxillae (Fig. 24) elongate ; palps two-segmented ; slender, falcate denticles on galealaciniae.

Labium (Fig. 25) with three-segmented palps ; segment 1 elongate and slender, as long as segments 2 and 3 combined; segment 2 with elongate and acute distomedial process ; segment 3 distolaterally acute, becoming excavated distomedially ; glossae longer than paraglossae, elongate and broad, apically round, without setae dorsally ; paraglossae subequal to glossae, arched, elongate, and slender, distally acute.

\section{- Thorax}

Hindwingpads absent.

Midsternum with small spur (Figs 32-33).

Legs (Fig. 26) without villopore ; femora elongate, distally round, anterior and posterior margins subparallel ; tibiae elongate, subequal to femora ; tarsal claws (Fig. 34) elongate, with two rows of denticles.

\section{- Abdomen}

Terga without scales or scale bases (as in Fig.9).

Gills (Figs 27-28) on abdominal segments 1-7, elongate.

Paraproct (Fig. 29) without prolongation.

Three caudal filaments present ; cerci with three to four elongate, sharp spines laterally every four segments (Fig.30) ; terminal filament as long as cerci.

\section{Alate stages \\ Unknown.}

\subsection{Etymology}

We name this genus after R.D. Waltz, former student of the first author of the genus, for his extensive contributions to the understanding of baetids. The generic name is masculine, and consists of an arbitrary combination of our colleague's last name and the Greek word zoyphion (diminutive of zoon, or animal). It thus means «Waltz's little animal».

\subsection{Type species}

Waltzoyphius fasciatus McCafferty \& Lugo-Ortiz, n. sp.

\subsection{Distribution}

\section{Brazil :Amazonas, Pará ; Paraguay.}

\subsection{Discussion}

Larvae of Waltzoyphius can be readily distinguiished among baetids by the presence of a medial spur on the midsternum (Figs 32-33). The maxillae (Fig. 24) are distinctive in that they are elongate and robust, and only have sharp, slender denticles on the galealaciniae. The labium (Fig. 25) shows a distinctive combination of broad, elongate glossae ; slender, elongate paraglossae ; and palp segments 2 with an elongate, acute distomedial process.

The basally-separated incisors place Waltzoyphius in Cloeoninae rather than Baetinae. Also, the presence of spines every four segments appears to be consistent with most other Cloeoninae. The lack of punctures in the cuticle and round femoral apices exclude it from Callibaetinae. Precise relationships within Cloeoninae cannot be ascertained at this moment because most of the characters that distinguish Waltzoyphius consist of autapomorphies.

\subsection{Waltzoyphius fasciatus McCafferty \& Lugo-Or- tiz, n.sp.}

\subsubsection{Description}

\section{Mature larva}

Body length : 4.1-5.0 mm ; caudal filaments : 2.1-2.3 $\mathrm{mm}$. General color yellow-brown.

- Head

Coloration yellow-brown, with no distinct pattern.

Antennae nearly twice length of head capsule.

Labrum (Fig. 31) with cluster of long, fine, simple setae on each side of midline.

\section{Hypopharynx as in Figure 21.}

Left mandible (Fig. 22) with eight denticles on outer set incisors and one robust denticle on inner set. Right mandible (Fig. 23) with four denticles on outer set of incisors and with two denticles on inner set of incisors.

Maxillae (Fig. 24) with palps extending beyond galealaciniae ; three to four slender, falcate denticles on galealaciniae and one row of 10-12 long, simple setae at base of galealaciniae ; four to five long, simple setae medially in midregion.

Labium (Fig. 25) with palp segments 2 and 3 with scattered fine, simple setae on outer and medial margins ; glossae with one row of short, simple setae on outer margin and scattered short, simple setae ventrally ; paraglossae with one row of long, simple setae on outer margin and one row of long, simple setae ventrally near medial margin.

- Thorax

Coloration yellow-brown, with no distinct pattern.

Legs (Fig. 26) yellow-brown; femora dorsally and ventrally with scattered short, simple setae, and with light brown band subdistally; tibiae dorsally and ven- 

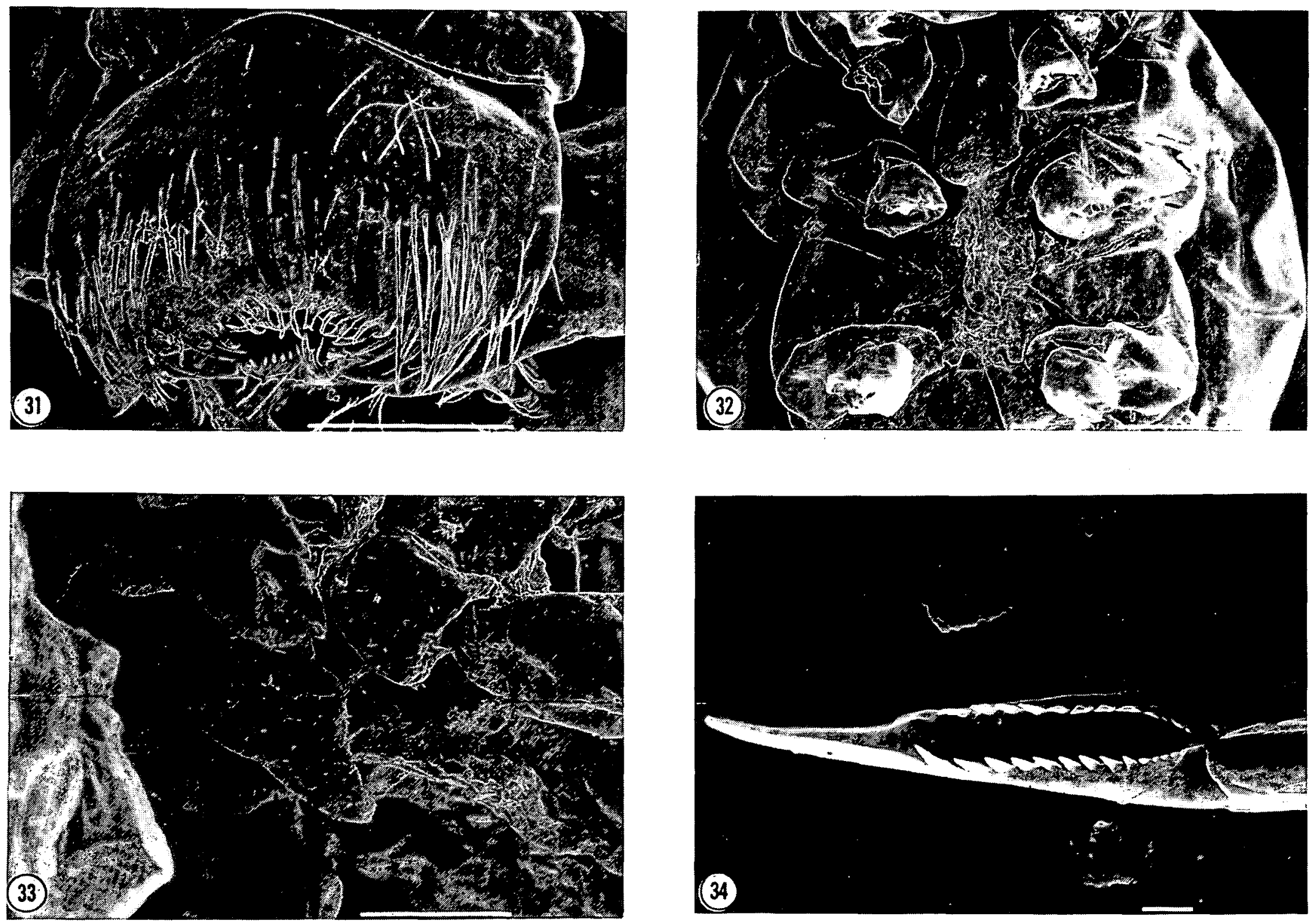

Fig. 31 to 34. Structures of Waltzoyphius fasciatus, larvae. $31:$ labrum $($ bar $=100 \mu \mathrm{m}) .32:$ midsternal spur $($ ventral $)($ bar $=100 \mu \mathrm{m}) .33:$ midsternal spur (frontolateral) $(\mathrm{bar}=100 \mu \mathrm{m}) .34:$ tarsal claw $(\mathrm{bar}=10 \mu \mathrm{m})$.

Fig. 31 à 34. Structures larvaires de Waltzoyphius fasciatus. 31 : labre (échelle $=100 \mu \mathrm{m})$. 32 : éperon du mesosternum en vue ventrale (échelle $=100 \mu \mathrm{m}) .33:$ éperon du mesosternum en vue frontolatérale (échelle $=100 \mu \mathrm{m}) .34:$ griffe tarsale (échelle $=10 \mu \mathrm{m})$.

trally with row of short, simple setae, and with light brown subbasal and subdistal bands ; tarsi dorsally with few short, simple setae and ventrally with 14-16 simple setae, increasing in length distally ; tarsal claws (Fig. 34) with two rows of 12-14 denticles each, increasing in length distally.

\section{- Abdomen}

Coloration yellow-brown; terga 2 and 5 usually medium brown ; terga $2-9$ medium brown laterally on midregion. Sterna yellow-brown.

Posterior margins of terga with sharp, triangular spines.

Gills (Fig. 27) elongate, nearly $1.5 x$ length of corresponding segment, poorly tracheated, marginally serrate (Fig. 28).
Paraprocts (Fig. 29) with 12-13 sharp spines, increasing in length distally.

Caudal filaments yellow-brown, with broad subdistal medium brown band ; cerci with six or eight long, simple setae medially ; terminal filament with six or eight, long simple setae laterally on each segment.

\section{Alate stages}

\section{Unknown.}

\subsubsection{Material examined}

Holotype : Mature female larva, Paraguay, Departemento Paraguarí, Parque Nacional Ybycuí, Arroyo Mina, edge, 18-VII-1985, R.T. Bonace (PERC). Paratypes: One larva, Brazil, Amazonas State, Aracu Cr, $15 \mathrm{~km}$ from Manaus, rd nr Rio Branco, 8-VI-1962, E.J. 
Fittkau (ZS) ; five larvae,-Paraguay, Departemento Paraguarí, Parque Nacional Ybycuí, Arroyo Mina, edge, 2-IX-1984, R.T. Bonace (PERC) ; one larva, same data, except 2-VIII-1984 (USMN); three larvae, same data, except 2-X-1984 (PERC) ; one larva, same data, except pool, 18-VII-1985 (USNM) ; one larva, Paraguay, Departemento Paraguarí, Parque Nacional Ybycuí, Arroyo Karai-m', 28-X-1984, R.T. Bonace (PERC). Additional material : larvae, Brazil, Amazonas State, Rio Negro, at jct with cold water cr, Manaus, 14-XII-1960, E.J. Fittkau (ZS) ; larva, Brazil, Amazonas State, Cachoeira Cr, nr Rio Cuieiras, N of Manaus, 17-XII-1960, E.J. Fittkau (ZS) ; larvae, Brazil, Amazonas State, Cachoeira $\mathrm{Cr}$, nr Acampamento, $\mathrm{N}$ of Manaus, 18-IV1961, E.J. Fittkau (PERC) ; larvae, Brazil, Amazonas State, Barro Branco Cr, Reserva Duke, $\mathrm{N}$ of Manaus, 10-V-1961, E.J. Fittkau (PERC) ; larvae, Brazil, Amazonas State, Ponta Negra, Bica Cr, Rio Negro, $\mathrm{N}$ of Manaus, 23-VI-1961, E.J. Fittkau (PERC) ; larvae, Brazil, Amazonas State, Passarinho Cr, Reserva Duke, N of Manaus, 27-VI-1961, E.J. Fittkau (PERC) ; larvae, Brazil, Amazonas State, Aracu Cr, $15 \mathrm{~km}$ from Manaus, rd nr Rio Branco, 8-VI-1962, E.J. Fittkau (PERC) ; larvae, Brazil, Amazonas State, Passarinho $\mathrm{Cr}$, Roca Antônio, Santo Antônio, $15 \mathrm{~km} \mathrm{~N}$ of Manaus, 12-XII-1961, E.J. Fittkau (PERC) ; larva, Brazil, Amazonas State, Barro Branco Cr, Reserva Duke, $\mathrm{N}$ of Manaus, 16-V-1965, E.J. Fittkau (ZS) ; larvae, Brazil, Pará State, Mission, Rio Cururú, 12-V-1942, H. Sioli (PERC) ; larvae Brazil, Pará State, Tento Cr, 7-V-1946, H. Sioli (PERC) ; larvae, Brazil, Pará State, $2^{\circ}$ Caripé Cr, 16-VIII-1953, H. Sioli ; larva, Brazil, Pará State, Aterro Cr, $21.6 \mathrm{~km}$ from Bragança, 14-XI-1953, H. Sioli (PERC) ; larva, Brazil, Pará State, Akahe Cr, nr Tiriyos Mission, nr Brazil-Suriname border, 15-III1962, E.J. Fittkau, (ZS) ; larva, Paraguay, Departemento Cordillera, Colonia Piraretá, Arroyo Yhaguy Guazú, 15-VIII-1985, R.T. Bonace (PERC) ; larvae, Paraguay, Departemento Paraguarí : Parque Nacional Ybycuí, Arroyo Mina, edge, 20-IV-1984, R.T. Bonace (PERC) ; larvae, same data, except 2-X-1984 (PERC) ; larvae, same data, except 8-III-1984 (PERC) ; larvae, same data, except 2-VIII-1982 (PERC) ; larvae, same data, except 2-XII-1983 (PERC) ; larva, same data, except 4VI-1985 (PERC) ; larva, same data, except 2-IX-1984 (PERC) ; larvae, Paraguay, Departemento Paraguarí, Parque Nacional Ybycuí, tributary of Arroyo Corrientes, 26-I-1985, R.T. Bonace (PERC) ; larva, Paraguay, Departemento Paraguarí, Arroyo Corrientes, 25VII-1985, R.T. Bonace (PERC).

\subsubsection{Etymology}

The specific epithet is a Latin word meaning banded. It is an allusion to the brown banding on the legs and cerci.

\subsubsection{Discussion}

Waltzoyphius fasciatus shows several features that may prove to be of value for species differentiation. The denticulation of the outer incisors in both the left and right mandibles (Fig. 22-23) is peculiar, and it is possible that some variation may be found if new species are discovered. The color banding of the legs (Fig. 26) and caudal filaments may also serve to distinguish W. fasciatus. The spination of the paraprocts (Fig. 29) is somewhat regular, but it may be shown to vary in other species. The presence of elongate, sharp lateral spines on every fourth segment of the cerci (Fig. 30) may also differ in other species.

\section{Acknowledgments}

We thank G.F. Edmunds, Jr. (Salt Lake City, Utah) for the donation of the material used in this study. We also thank A. Thomas (Laboratoire d'Hydrobiologie, Toulouse, France) for the translation of the abstract and figure legends. The scanning electron microscope was made available by the Electron Microscope Center at Purdue University with support of NSF grant PCM-8400133. This paper has

been assigned Purdue Agricultural Research Program No. 14787.

\section{References}

Edmunds G.F. Jr. 1972. - Biogeography and evolution of Ephemeroptera. Annu. Rev. Entomol., 17:21-42.

Lewis W.M., Hampton S.K. \& Saunders J.F. 1995. - Rivers in northern South America. : 219-256. In Cushing C.E., Cummins K.W. \& Minshall G.W. (eds.), River and stream ecosystems. Elsevier, Amsterdam.

Lugo-Ortiz C.R. \& McCafferty W.P. - Aturbina georgei gen. et sp.n. : a small minnow mayfly (Ephemeroptera : Baetidae) without turbinate eyes. Aquat. Insects, in press.

McCafferty W.P. \& Waltz R.D. 1990. - Revisionary synopsis of the Baetidae (Ephemeroptera) of North and Middle America. Trans. Am. entomol. Soc., 116 (4) : 769-799.

McCafferty W.P. \& Waltz R.D. 1995. - Labiobaetis (Ephemeroptera : Baetidae) : new status, new North American species, and related new genus. Entomol. News, 106 (1) : 19-28.

McCafferty W.P., Flowers R.W. \& Waltz R.D. 1992. -The biogeography of Mesoamerican mayflies. Pp. 173-193. In : Darwin S.P. \& Welden A.L. (eds.), Biogeography of Mesoamerica : proceedings of a symposium. Tulane Univ. Stud. Zool. Bot., Suppl. Publ. 1 .

Waltz R.D. \& McCafferty W.P. 1985. - Moribaetis : a new genus of Neotropical Baetidae (Ephemeroptera). Proc. entomol. Soc. Wash., 87 (1) : 239-251

Waltz R.D. \& McCafferty W.P. 1987a. - Generic revision of Cloeodes and description of two new genera (Ephemeroptera : Baetidae). Proc. entomol. Soc. Wash., 89 (1) : 177-184.

Waltz R.D. \& McCafferty W.P. 1987b. - Revision of the genus Cloeodes Traver (Ephemeroptera : Baetidae). Ann. entomol. Soc. Am., 80 (2) : 192-207.

Waltz R.D., McCafferty W.P. \& Thomas A. 1994. - Systematics of Alainites n.gen., Diphetor, Indobaetis, Nigrobaetis, n.stat., and Takobia n.stat. (Ephemeroptera, Baetidae). Bull. Soc. Hist. nat. Toulouse, $130:$ 33-36. 